\title{
Randomised trial of iodine intake and thyroid status in preterm infants
}

\author{
Jenny Rogahn, Steven Ryan, John Wells, Bill Fraser, Christine Squire, Nick Wild,
} Adrian Hughes, Laweh Amegavie

Neonatal Unit, Liverpool Women's Hospital, Liverpool, UK

J Rogahn

Royal Liverpool Children's NHS Trust, Alder Hey Hospital, Liverpool

S Ryan

Department of Clinical Chemistry, Royal Liverpool University Hospital, Liverpool B Fraser

C Squire

Cow and Gate Nutricia Limited, Trowbridge, Wiltshire, UK

J Wells

Paediatric Department, Whiston Hospital, Merseyside, UK

L Amegavie

Paediatric Department, Arrowe Park Hospital, Merseyside

A Hughes

Paediatric Department, Warrington Hospital, Merseyside

$\mathrm{N}$ Wild

Correspondence to: Dr Ryan, RLC NHS Trust, Alder Hey Hospital, Liverpool L12 2AP, UK email: Steve.Ryan@ RLCH-TR.NWEST.NHS.UK

Accepted 28 April 2000

\begin{abstract}
Background-Low levels of circulating thyroid hormones have been associated with poorer general and neurodevelopmental outcome in preterm babies and it has been speculated that the association is causal. Low levels of circulating thyroid hormone have been reported after inadequate intake of iodine in preterm infants being fed milk formula.

Aim-To investigate whether increased iodine intake from supplemented preterm formula would improve thyroid hormone levels in preterm babies (this study) and hence improve neurodevelopmental status (planned subsequent study).

Method-A total of 121 preterm infants were entered into a randomised controlled trial of standard $(68 \mu \mathrm{g} / \mathrm{l})$ versus increased $(272 \mu \mathrm{g} / 1)$ iodine in preterm formula.

Results-The two groups were comparable at recruitment. No evidence of an effect of the intervention on thyroid hormone levels was seen up to 41 weeks after conception.

Conclusion-Calls for increased iodine content of preterm infant formulas are not justified by this study.
\end{abstract}

(Arch Dis Child Fetal Neonatal Ed 2000;83:F86-F90)

Keywords: premature; randomised controlled trial; iodine; thyroid function; milk formula

It is well documented that preterm babies have reduced serum total thyroxine levels compared with term babies, and many are consequently hypothyroxinaemic. ${ }^{12}$ The degree of hypothyroxinaemia is related to the severity of neonatal disease and in particular the severity of respiratory distress syndrome, ${ }^{2-4}$ and, unsurprisingly, low thyroxine levels are more often seen at lower gestation and birth weight. ${ }^{25}$ Preterm infants also have low total triiodothyronine levels compared with term infants. ${ }^{6-8}$ In sick preterm infants, especially those with respiratory distress syndrome, these levels are further reduced. ${ }^{34}$ The lower reference value for triiodothyronine concentration is only reached in one third of sick babies $<1200 \mathrm{~g}$ within four weeks of birth. ${ }^{8}$ Low thyroxine occurs in one third of preterm neonates by six weeks. ${ }^{2}$ However, these low thyroid hormone levels are transient, spontaneously resolving after 8 weeks of age. ${ }^{16}$

Such decreases in total thyroid hormone levels are also well documented in acutely unwell adults in intensive care; free thyroxine levels increase initially and fall later in the illness. This change is now thought to be an inherent part of the adaptive stress response. The situation in preterm infants is somewhat different. Thyroid hormones have an important role in neurological development in the perinatal period and early infancy when there is a theoretically greater risk of dietary iodine deficiency. An association between delay in neural maturation, neurological development, and low thyroid hormone levels has been shown on a number of occasions and it has been suggested that the association may be causal, ${ }^{5-10}$ suggesting that treatment to increase thyroid hormones may be appropriate to reduce the risk of subsequent developmental delay. Others argue that the phenomenon is an expression of temporary hypothalamic-pituitary immaturity or a manifestation of non-thyroidal illness not requiring any treatment, as low thyroxine concentrations are associated with either normal or thyroid stimulating hormone (thyrotrophin) concentrations. ${ }^{2}{ }^{4}$ However, two studies of the effects of giving thyroxine to preterm infants with hypothyroxinaemia did not show any clear developmental advantage, with one study showing a mental development score some 10 points lower in a subgroup of infants. ${ }^{11}{ }^{12}$

The commonest worldwide cause of hypothyroidism in infants is iodine deficiency, and this is a major cause of preventable mental retardation. As preterm babies have had their maternal iodine supply severed, and therefore depend on an external supply postnatally at a time of rapid brain growth, they may be considered to be at particular risk. Previous studies have illustrated how preterm infants are not meeting the dietary reference value for iodine and subsequently appear to be hypothyroxinaemic as the result of a relative iodine deficiency. ${ }^{13}{ }^{14}$ For the sake of simplicity, the intakes of iodine recommended by various bodies, which are now discussed, will be arbitrarily converted to iodine intakes in $\mu \mathrm{g} / \mathrm{kg} /$ day. In term infants up to 6 months of age, the previous recommended daily allowance for iodine in Europe and the United States was about $6 \mu \mathrm{g} / \mathrm{kg} /$ day. ${ }^{15-17}$ From 1992, the 
recommended intake for term infants was increased to about $14 \mu \mathrm{g} / \mathrm{kg} /$ day. ${ }^{18}$ The European Society of Paediatric Gastroenterology and Nutrition recommended an intake of about 12 $\mu \mathrm{g} / \mathrm{kg} /$ day in preterm infants, and, more recently, Ares and colleagues have called for the intake to be increased to $30 \mu \mathrm{g} / \mathrm{kg} /$ day ${ }^{13}{ }^{19}$ As the iodine content of preterm formula varies from 8 to 20 $\mu \mathrm{g} / \mathrm{dl}$, only an iodine content near the top of this range will meet these suggested intakes. Preterm human milk provides about $15 \mu \mathrm{g} / \mathrm{kg} /$ day. ${ }^{13}$

We hypothesised that iodine deficiency was partly responsible for low levels of thyroid hormones found in preterm babies and that improving iodine intake would lead to increased circulating thyroid hormones.

The aim of this study was to examine whether an increased iodine intake (40-50 $\mu \mathrm{g} / \mathrm{kg} /$ day $v 12-16 \mu \mathrm{g} / \mathrm{kg} /$ day) using specially prepared preterm infant formula would result in improved biochemical thyroid hormone levels and subsequent improved growth in preterm infants less than 33 weeks gestation.

\section{Patients and methods}

Ethical approval was granted for all the centres participating, and written informed parental consent obtained.

Premature infants <33 weeks gestation admitted between May 1997 and October 1998 to neonatal units at Liverpool Women's Hospital, Aintree Hospital, Whiston Hospital, Arrowe Park Hospital and Warrington Hospital (all in the Mersey Region UK) were eligible for the trial. Infants were excluded if transferred from or to units not involved in the study, if they failed to achieve full enteral feeding in the time limits specified, if their parents failed to understand English, or if they had a severe congenital malformation. Gestational age was obtained from maternal dates and early prenatal ultrasound assessment, and where there was any discrepancy of more than 2 weeks, these infants (two) were not recruited.

Neonates were randomised to a high or low iodine formula, once they were clinically stable and receiving all their nutrition enterally by 2 weeks of age if $>28$ weeks gestation and by 31 weeks after conception if $\leqslant 28$ weeks gestation. Infants who had received full enteral feeds within the time specified, but who later developed feeding intolerance requiring intravenous fluid, continued in the study based on an intention to treat policy. Randomisation was stratified according to birth weight $(<1000 \mathrm{~g}$ and $\geqslant 1000 \mathrm{~g}$ ) using a two and four block design generated by randomised number tables by Nutricia Ltd and sealed in opaque envelopes.

In line with current infant feeding philosophy, breast feeding is the preferred choice, and as such is positively encouraged on each of the neonatal units participating in this study. On these units, most breast fed preterm babies $<33$ weeks gestation require some infant formula supplementation, and eventually the majority receive most of their nutrition from formula rather than breast milk. Therefore such infants were considered eligible for the trial, and supplementary formula feeding was given as one of the trial formulas. There is no donor milk supply at any of the hospitals taking part. Given that most of the milk that such babies were likely to receive was formula, we judged that the data for such babies should be incorporated in the main findings of the study on an intention to treat basis. We only expected a small number of babies to be completely fed with their own mother's breast milk.

Trial formula continued to be given until the infants were between 40 and 41 weeks post menstrual age, and when infants were discharged home before this, milk was provided in bottles for use in the home. Bottles were colour coded into the two types and were otherwise indistinguishable. The iodine content was varied at the point of manufacture and subject to quality control analysis from randomly sampled bottles from each batch produced. It should be noted that some of the iodine content of the formula arises from the use of iodine as an antiseptic in the dairy industry, and achieving extreme accuracy and precision in measurements of iodine content can be difficult.

\section{MEASUREMENTS}

Baseline data were collected to allow stratification by birth weight, to ensure comparability of the groups after randomisation, and to provide an accurate description of the cohort studied. The baseline data collected included the following: birth weight, presence of intrauterine growth retardation, gestation, sex, delivery mode, prolonged rupture of the membranes $>24$ hours, administration of antenatal corticosteroids, Apgar scores at one and five minutes, whether intubated at birth, and administration of artificial surfactant.

Outcome data included number of days ventilated, number of days of continuous positive airways pressure, number of days in additional oxygen, additional oxygen requirement at 36 weeks post menstrual age, duration of hospital stay, number of days until completing the study, presence of intraventricular haemorrhage on ultrasound, and presence of parenchymal cysts.

Dietary and growth data collected for each infant included: duration of parenteral nutrition in days, duration of human milk feeding in days, daily milk intake in $\mathrm{ml}$ (infants were demand fed), weight in g (measured weekly), occipitofrontal circumference in $\mathrm{cm}$ (measured weekly), and leg length in $\mathrm{mm}$ (measured weekly using knemometry). ${ }^{20}{ }^{21} \mathrm{~A}$ validation project was carried out by JR, and all measurements of leg length were performed by the same researcher. The same researcher in the community recorded occipitofrontal circumference. Weight was measured by the staff in each hospital during the infant's stay and by the midwife/health visitor in the community. The total amount of formula ingested $(\mathrm{ml} / \mathrm{kg})$ at 30 , 35, and 40 weeks was recorded.

Baseline blood thyroid hormone concentrations were measured and analysed at 2 weeks of age if $>28$ weeks post menstrual age and by 31 weeks post menstrual age if $\leqslant 28$ weeks post menstrual age. Subsequent tests were per- 
Table 1 Baseline data comparing infants randomised to lower iodine versus higher iodine milk

\begin{tabular}{lll}
\hline & Lower iodine & Higher iodine \\
\hline Number of cases & 60 & 61 \\
Sex (F:M) & $27: 33$ & $35: 26$ \\
Gestation (completed weeks) & $30(25-32)$ & $30(24-32)$ \\
Birth weight (g) & $1363(724-2080)$ & $1520(530-2100)$ \\
Intrauterine growth retardation <3rd centile & 11 & 11 \\
Apgar score at & & $7(1-10)$ \\
$\quad$ minute & $8(1-10)$ & $9(4-10)$ \\
$\quad 5$ minutes & $9(2-10)$ & 33 \\
Caesarean section & 18 & 17 \\
Prolonged rupture of membranes & 56 & 57 \\
Antenatal steroids received & 42 & 37 \\
Respiratory distress syndrome & 38 & 36 \\
Administration of surfactant & 38
\end{tabular}

Values are numbers of cases or median (range). No significant intergroup differences were observed.

Table 2 Outcomes of infants randomised to lower iodine versus higher iodine formula

\begin{tabular}{lll}
\hline Outcome & Lower iodine & Higher iodine \\
\hline Days ventilated & $1(0-72)$ & $1(0-72)$ \\
Days increased $\mathrm{FIO}_{2}$ & $5.5(0-108)$ & $3(0-112)$ \\
Receiving oxygen at 36/40 & 24 & 16 \\
Days intravenous fluid & $12(1-30)$ & $11(1-56)$ \\
Received breast milk & 26 & 32 \\
Intraventricular haemorrhage grade III-IV & 2 & 0 \\
Cystic periventricular leucomalacia & 2 & 1 \\
In patient stay (days) & $42.5(14-108)$ & $43(14-106)$ \\
\hline
\end{tabular}

Values are numbers or median (range). No significant intergroup differences were observed.

formed at 35-36 weeks and 40-41 weeks post menstrual age. The first two samples were taken when possible with routine blood samples on the neonatal units, and the third was generally taken in the community by heel prick. A $1 \mathrm{ml}$ sample of clotted blood providing 0.5 $\mathrm{ml}$ serum was taken for the thyroid function tests. Thyrotrophin, total thyroxine, total triiodothyronine and, when possible, free thyroxine were measured using Vitros ECi Immunodiagnostic Reagents (Ortho-Clinical Diagnostics, Amersham, Bucks, UK); analysis was blind to trial allocation. The maximum coefficients of variation of the thyroid hormone assays were as follows: total thyroxine, $3.0 \%$; total triiodothyronine, $2.8 \%$; free thyroxine, $4.1 \%$; thyrotrophin, $4.5 \%$. These coefficients are based on between batch values, and as each baby's samples were analysed in the same batch, the precision is likely to have been greater.

STATISTICAL ANALYSIS

Sample size was estimated from two previous studies using a standard power (0.8) and significance (0.05)..$^{22}$ The standard deviation for thyrotrophin is $5 \mathrm{mU} / \mathrm{l}$ in a preterm population, and an expected difference of half of this value can be postulated from the known relation between iodine intake and thyrotrophin levels. ${ }^{13}{ }^{14}$ An estimated sample size of 136 patients can be calculated from these variables. It should be noted that this standard deviation is regarded as wide, and was consequently felt to overestimate the sample size. Similar estimations for total thyroxine (expected difference 15-20 nmol/1 and SD 25 nmol/l) gives an estimated sample size of between 49 and 87 patients. Reduction of incidence of low total triiodothyronine level $(<1.2 \mathrm{nmol} / \mathrm{l})$ at 6 weeks of age from $55 \%$ to $15 \%$ has been associated with adequate iodine intake, ${ }^{13}$ and a more conservative reduction from $55 \%$ to $33 \%$ would require 116 patients. We aimed to recruit 120 babies to the study.

Intergroup differences were examined by Mann-Whitney $\mathrm{U}$ test, $t$ test, and $\chi^{2}$ test for non-normal continuous variables, normal continuous variables, and categorical variables respectively.

\section{Results}

A total of 121 premature infants out of a possible 442 eligible babies were recruited and randomised to the multicentred double blind study over a period of 17 months from May 1997 to October 1998. Sixty one babies were recruited from Liverpool Women's Hospital Neonatal Unit, a large regional unit. Twenty one were recruited from Arrowe Park Hospital Neonatal Unit, 19 from Aintree Hospital Neonatal Unit, 10 from St Helens and Knowsley Hospital Special Care Unit, and 10 from Warrington Hospital Neonatal Unit. In total, 321 infants were not recruited; for 179 of these, the parents refused consent predominantly because of the extra blood tests necessary; 48 were transferred from or to hospitals not participating in the study; 42 died either before 2 weeks of age or before 30 weeks gestation if $<28$ weeks gestation; 41 did not achieve full feeding within the time limits specified; seven had congenital anomalies; two parents did not understand English; two infants were excluded because of ethical considerations (one mother died and one infant was for adoption).

Of the 121 infants recruited, 17 in total were stratified as $<1000 \mathrm{~g}$ (eight boys and nine girls) and 104 as $\geqslant 1000 \mathrm{~g}$ ( 51 boys and 53 girls). Six infants were withdrawn from the study (four boys $>1000 \mathrm{~g}$ at age $17,21,33$, and 53 days, and two girls $>1000 \mathrm{~g}$ at days 18 and 50). One of the girls was taken off the trial milk (lower iodine) on day 50 as the result of a medical decision, but, as parental consent was not withdrawn, growth data and thyroid function tests were completed. One boy $<1000 \mathrm{~g}$ died because of extreme prematurity ( 25 weeks gestation) at 72 days, but received only breast milk. Eight infants (one girl $<1000 \mathrm{~g}$ and three boys and four girls $\geqslant 1000 \mathrm{~g}$ ) received breast milk only, until 40 weeks. Four infants in total received $>50 \%$ breast milk (two boys $<1000 \mathrm{~g}$ and two girls $\geqslant 1000 \mathrm{~g}$ ). The data for these infants were included in the initial analyses based on an intention to treat basis. In a subanalysis, these data were excluded.

The study was completed by 114 infants, and 102 infants received the trial milk until 40 weeks. Full growth data and thyroid function results were collected for all these infants. Of the 114 infants, 16 were $<1000 \mathrm{~g}$ (seven boys and nine girls) and $98 \geqslant 1000 \mathrm{~g}$ (47 boys and 51 girls).

Of the 121 infants originally randomised, 60 were randomised to lower iodine milk and 61 to higher iodine. The median (range) intake of trial milk formula for the higher iodine group was $23.7(0-46.9)$ litres and for the lower iodine group $21.7(0-43.4)$ litres. These values were not significantly different. Of the infants 
Table 3 Nutrition/growth data comparing infants randomised to lower iodine versus higher iodine milk

\begin{tabular}{|c|c|c|}
\hline & Lower iodine & Higher iodine \\
\hline \multicolumn{3}{|l|}{ Volume of trial milk (ml/kg) } \\
\hline 30 weeks & $153(0-200)$ & $117(0-207)$ \\
\hline 35 weeks & $151(0-298)$ & $153(0-304)$ \\
\hline 40 weeks & $198(0-379)$ & $190(0-338)$ \\
\hline \multicolumn{3}{|l|}{ Weight $(\mathrm{g})$} \\
\hline 30 weeks & $1390(844-2080)(n=60)$ & $1530(710-2100)(\mathrm{n}=61)$ \\
\hline 35 weeks & $2030(1300-2690)(n=59)$ & $2120(1330-2890)(n=60)$ \\
\hline 40 weeks & $3200(2040-4200)(\mathrm{n}=58)$ & $3180(2360-4000)(\mathrm{n}=57)$ \\
\hline \multicolumn{3}{|l|}{ Lower leg length (mm) } \\
\hline 30 weeks & $65.1(51.8-78.2)(n=60)$ & $67.9(44.4-84.9)(\mathrm{n}=61)$ \\
\hline 35 weeks & $74.3(59.9-84.5)(\mathrm{n}=59)$ & $75.1(56.1-91.1)(\mathrm{n}=60)$ \\
\hline 40 weeks & $89.3(75.5-100.8)(n=58)$ & $90.2(77.3-103.1)(\mathrm{n}=57)$ \\
\hline \multicolumn{3}{|l|}{ Head circumference ( $\mathrm{mm}$ ) } \\
\hline 30 weeks & $28.1(23-31.8)(n=59)$ & $28.4(24.5-31.4)(n=60)$ \\
\hline 35 weeks & $31.8(28-34.2)(\mathrm{n}=59)$ & $31.4(27.5-34)(\mathrm{n}=60)$ \\
\hline 40 weeks & $35.9(32.4-38)(n=58)$ & $35.5(32.4-38.4)(n=57)$ \\
\hline Weight gain (g/day) & $25.5(9-37)(n=58)$ & $25(14-37)(n=57)$ \\
\hline Lower leg length gain ( $\mathrm{mm} /$ day) & $0.45(0.26-0.63)(\mathrm{n}=58)$ & $0.43(0.24-0.58)(\mathrm{n}=57)$ \\
\hline Head circumference growth ( $\mathrm{cm} /$ week) & $0.78(0.53-1.3)(\mathrm{n}=58)$ & $0.75(0.4-1.1)(\mathrm{n}=57)$ \\
\hline
\end{tabular}

Data are presented as median (range) at 30,35, and 40 weeks after conception. No significant intergroup differences were observed.

Table 4 Mean (SD) levels of thyroid hormones in the two groups at 30, 35, and 40 weeks after conception

\begin{tabular}{|c|c|c|}
\hline & Lower iodine & Higher iodine \\
\hline \multicolumn{3}{|c|}{ Total thyroxine $(\mathrm{nmol} / \mathrm{l})$} \\
\hline 30 weeks & $102(35)(n=59)$ & $105(33)(n=60)$ \\
\hline 35 weeks & $120(24)(\mathrm{n}=54)$ & $120(31)(\mathrm{n}=56)$ \\
\hline 40 weeks & $126(26)(\mathrm{n}=56)$ & $124(28)(\mathrm{n}=57)$ \\
\hline \multicolumn{3}{|c|}{ Total triiodothyronine $(\mathrm{nmol} / \mathrm{l})$} \\
\hline 30 weeks & $1.47(0.57)(\mathrm{n}=57)$ & $1.49(0.43)(\mathrm{n}=58)$ \\
\hline 35 weeks & $2.00(0.40)(\mathrm{n}=54)$ & $2.01(0.38)(\mathrm{n}=55)$ \\
\hline 40 weeks & $2.59(0.48)(\mathrm{n}=56)$ & $2.70(0.47)(n=54)$ \\
\hline \multicolumn{3}{|c|}{ Free thyroxine $(\mathrm{pmol} / \mathrm{l})$} \\
\hline 30 weeks & $18.1(8.5)(n=43)$ & $17.0(5.5)(\mathrm{n}=52)$ \\
\hline 35 weeks & $18.6(7.2)(\mathrm{n}=50)$ & $17.5(4.7)(\mathrm{n}=50)$ \\
\hline 40 weeks & $15.4(3.6)(\mathrm{n}=55)$ & $15.0(3.1)(\mathrm{n}=52)$ \\
\hline \multicolumn{3}{|c|}{ Thyrotrophin (mU/l) } \\
\hline 30 weeks & $2.16(1.58)(\mathrm{n}=58)$ & $1.86(1.04)(n=59)$ \\
\hline 35 weeks & $2.13(1.58)(\mathrm{n}=54)$ & $1.93(0.91)(\mathrm{n}=54)$ \\
\hline 40 weeks & $2.36(0.90)(\mathrm{n}=55)$ & $2.44(1.02)(\mathrm{n}=56)$ \\
\hline
\end{tabular}

No significant intergroup differences were observed.

who were withdrawn or died before 40 weeks, five were randomised to lower iodine and two to higher iodine. Three infants randomised to the lower iodine group and five to the higher iodine group received only their own mother's breast milk and did not require any supplementary formula. They were included in the primary analysis. Of the four infants who received between $50 \%$ and $99 \%$ of their milk as mother's own breast milk, three were randomised to higher iodine milk and one to lower iodine. They too were included in the primary analysis. The characteristics of the infants in the two groups were similar, and no significant intergroup differences were observed (table 1). Table 2 shows the data on infant morbidity. There were no significant differences between the two groups. Table 3 illustrates the nutritional and growth data for the two groups. No significant difference was observed for any measurement.

Within the two groups, infants who were fed any breast milk throughout their stay were lighter at 40 weeks gestation (median weight $2565 \mathrm{~g}$ ), shorter (median lower leg length 83.4 $\mathrm{cm}$ ), and with a smaller head circumference $(34.6 \mathrm{~cm})$. They also had a smaller weight gain $(16 \mathrm{~g} /$ day $)$ and leg length gain $(0.35 \mathrm{~mm} /$ day $)$. Thirty five babies were receiving only expressed breast milk at 30 weeks after concep-
Key message

- Increasing milk iodine content in line with the latest recommendations for preterm babies had no effect on thyroid hormone levels in the perinatal period

tion, 13 (five in the lower iodine group and eight in the higher iodine group) at 35 weeks, and eight at 40 weeks.

No significant differences in thyroid hormone levels were observed between the two groups (table 4). There was no effect of intrauterine growth retardation, prolonged rupture of membranes, or antenatal steroids. Nor was there any difference in the subgroup of patients $<1000$ g. Numbers of babies with significant intraventricular or parenchymal abnormalities were too small to investigate the effect of such abnormalities on thyroid function. There was no systematic effect of breast milk feeding on thyroid function. Repeat analysis after removal of data for breast fed babies did not alter the negative findings of the study.

The intended iodine content of the two formulas had been $80 \mu \mathrm{g} / 1$ for the lower iodine formula and $250 \mu \mathrm{g} / \mathrm{l}$ for the higher iodine formula. Subsequent quality control analyses showed the mean contents to be 68 and 272 $\mu \mathrm{g} / 1$ respectively.

\section{Discussion}

PRINCIPAL FINDINGS

Our hypothesis that increased iodine intake in preterm infants would improve circulating concentrations of thyroid hormones was unproven. It is unlikely that this has resulted from a type II error-that is, the study being too small to detect a meaningful differencebecause the thyroid hormone levels in the two groups were so similar. The study thus suggests "evidence of no effect". Neither did the intended subanalysis show any difference between the two groups. Hence it seems that the lower intake of iodine of $68 \mu \mathrm{g} / \mathrm{l}$ is adequate compared with the higher dose of $272 \mu \mathrm{g} / 1$.

STRENGTHS AND WEAKNESSES OF THE STUDY The strengths of the study include an adequate sample size and a full description of not only those infants who entered the study but also those who were eligible and did not enter the study. The recruitment rate of around one quarter of eligible babies was realistic and had been calculated at the beginning of the study. We felt that, by being very "neutral" when recruiting, the parents recruited were well informed and more likely to continue with the study after discharge, and this was born out by the low withdrawal rate. The results were primarily analysed on an intention to treat basis, but they were not altered by subanalysis. The initial analysis of the results was undertaken blind, and coauthors were asked to comment on the initial analysis and suggest any further analysis before the code was broken. 
STRENGTHS AND WEAKNESSES COMPARED WITH OTHER STUDIES

This study particularly follows on from the work of Ares and colleagues who had shown that, in Spanish preterm babies, iodine intake was suboptimal in those fed formula milk. ${ }^{13}$ They also showed that there was a correlation between low gestation and low levels of circulating thyroid hormones. ${ }^{13}{ }^{14}$ These initial studies were observational and relied on the demonstration of association, the authors then postulating that a causal association was biologically plausible. The present large study, which accounted for known (and to an extent unknown) confounding variables, found no evidence of such an association. The logical conclusion of the studies of Ares and colleagues is that iodine content of infant milk formulas should be increased in line with international recommendations, but our randomised controlled trial does not support this conclusion. We did not investigate iodine status by measuring concentrations in urine, so it is impossible to comment on any differences in iodine status between our population and the Spanish population.

MEANING OF THE STUDY

Thyroid status in preterm babies has been investigated often, and a coherent picture has now emerged. ${ }^{22}$ Preterm babies develop low levels of circulating thyroid hormones, and these low levels are predictive of adverse outcome even when gestation and birth weight are taken into account. Understandably, trials of thyroid hormone replacement have been undertaken, and, as no conclusive proof of benefit has been found, further trials have been called for, especially in the most immature infants. ${ }^{23}$ Our study fails to show any benefit of increased iodine intake on thyroid hormone concentrations. Hence there is currently no imperative for modifying thyroid function in preterm babies, by diet or hormone treatment. In our study, only 17 of 121 babies had a birth weight $<1000 \mathrm{~g}$, and the study could therefore be criticised for not investigating the babies at highest risk of hypothyroidism and associated neurodevelopmental impairment; however, even a subanalysis of this group showed no difference. Not many such babies were recruited because it was not possible for them to tolerate the milk based intervention because they were so sick. However, van Wassenaer and colleagues $^{23}$ have shown a benefit to the later Bayley mental development index after neonatal thyroxine treatment in a subpopulation of preterm infants $<27$ weeks. There is still therefore some scope for considering trials of iodine supplementation in very preterm neonates, but other delivery systems including the use of the parenteral route will be needed. In terms of infant preterm formula iodine content, the suggestion from Ares and coworkers of the need for increased milk iodine content is not borne out.

UNANSWERED QUESTIONS AND FUTURE RESEARCH The difference between our findings and those of Ares et al is unexplained and could be answered by further studies of iodine supple- mentation. The whole question of the role of the pituitary-thyroid axis in health and disease in preterm neonates remains unclear, and a better understanding of this role is required before further intervention studies are undertaken.

We acknowledge Cow and Gate Nutricia Limited, the nursing staff of the participating neonatal units, and the technical staff of the Department of Clinical Chemistry.

Conflict of interest: The study was financially supported by Conflict of interest: The study
Cow and Gate Nutricia Limited.

1 Cuestas RA. Thyroid function in healthy premature infants. 7 Pediatr 1978;92:963-5.

2 Mercado M, Yu VYH, Szymonowicz W, Gold H. Thyroid function in very preterm infants. Early Hum Dev 1988;1:131-6.

3 Diamond FB, Parks JS, Tenore A, Marino JM, Bongiovanni AM. Hypothyroxinemia in sick and well preterm infants. Clin Pediatr 1979;18:555-61.

4 Hadeed AJ, Asay LD, Klein AH, Fisher DA. Significance of transient postnatal hypothyroxinemia in premature infants with and without respiratory distress syndrome. Pediatrics with and without

5 Meijer WJ, Verloove-Vanhorick SP, Brand R, van den Brande J. Transient hypothyroxinaemia associated with developmental delay in very preterm infants. Arch Dis Child 1992;67:944-8.

6 Jacobsen BB, Andersen HJ, Peitersen AB, Dige-Petersen H, Hummer L. Serum levels of thyrotropin, thyroxine and triiodothyronine in full term, small-for-gestational age and preterm newborn babies. Acta Paediatr Scand 1977;66:681-7.

7 Uhrmann S, Marks KH, Maisels MJ, et al. Thyroid function in the preterm infant: a longitudinal assessment. $\mathcal{F}$ Pediatr 1978;92:968-72.

8 Lucas A, Rennie J, Baker BA, Morley R. Low plasma triiodothyronine concentrations and outcome in preterm infants. Arch Dis Child 1988;63:1201-6.

9 Den OA, Kok JH, Verkerk PH, Brand R, VerlooveVanhorick SP. The relation between neonatal thyroxine levels and neurodevelopmental outcome at age 5 and 9 years in a national cohort of very preterm and/or very low birth weight infants. Pediatr Res 1996;39:142-5.

10 de Vries LS, Heckmatt JZ, Burrin JM, Dubowitz LM, Dubowitz V. Low serum thyroxine concentrations and neural maturation in preterm infants. Arch Dis Child 1986;61:862-7.

11 Van Wassenaer AG, Kok JH, De Vijlder JJM, et al. Effects of thyroxine supplementation on neurologic development in infants born at less than 30 weeks' gestation. $N$ Engl f Med 1997;336:21-6.

12 Chowdhry P, Scanlon JW, Auerbach R, Abbassi V. Results of controlled double-blind study of thyroid replacement in very low-birth-weight premature infants with hypothyroxinemia. Pediatrics 1984;73:301-5.

13 Ares S, Quero J, Duran S, Presas MJ, Herruzo R, de Escobar GM. Iodine content of infant formulas and iodine intake of premature babies: high risk of iodine deficiency. Arch Dis Child 1994;71:F184-91.

14 Ares S, Escobar-Morreale HF, Quero J, et al. Neonatal hypothyroxinemia: effects of iodine intake and premature hypothyroxinemia: effects of iodine intake and p

15 Food and Nutrition Board of the National Academy of Sciences and National Research Council. Recommended daily amounts. 10th ed. Washington DC: National Academy Press 1989;213-17.

16 American Academy of Pediatrics. Committee on Nutrition. Nutritional needs of low birthweight infants. Paediatrics 1985;60:519-30.

17 ESPGAN Committee on Nutrition. Guidelines on infant nutrition. Recommendation for the composition of an adapted formula. Acta Paediatr Scand 1977;262:S1-20.

18 Recommendations on iodine nutrition for mothers and infants in Europe. In: Delange F, Dunn JT, Glinoer D, eds. Iodine deficiency disorders in Europe: a continuing concern. New York: Plenum Press, 1993:471-8.

19 Bremer HJ, Brooke OG, Orzalesi M, et al. Nutrition and feeding of preterm infants. Committee on Nutrition of the Preterm Infant, European Society of Paediatric GastroenPreterm Infant, European Society of Paediatric Gastroen1987;336:S1-14.

20 Gibson AT, Pearse RG, Wales JKH. Knemometry and the assessment of growth in premature babies. Arch Dis Child 1993; 69: 498-504.

21 Michaelsen KF, Skov L, Badsberg JH, Jorgenson M. Short term measurement of linear growth in preterm infants: validation of a hand held knemometer. Pediatr Res 1991;30:464-8.

22 Lafranchi S. Thyroid function in the preterm infant. Thyroid 1999:9:71-8.

23 Van Wassenaer AG, Kok JH, Briet JM, Pijning AM, de Vijlder JJ. Thyroid function in very preterm newborns: possible implications. Thyroid 1999;9:85-91. 